\title{
Karaciğer ve Böbrek Nakli Olan Çocuk Hastada Plesiomonas Shigelloides Gastroenteriti
}

\section{Plesiomonas Shigelloides Gastroenteritis in Child with Liver and Kidney Transplantation}

\author{
Nadire Beyza Can $^{1}$ (D), Hatice Kübra Dursun² ${ }^{2}$, Önder Yavaşcan \\ ${ }^{1}$ istanbul Medipol Üniversitesi, Tıp Fakültesi, İstanbul, Türkiye \\ ${ }^{2}$ Istanbul Medipol Üniversitesi, Tıp Fakültesi, Çocuk Sağlı̆̆ı ve Hastalıkları, İstanbul, Türkiye \\ ${ }^{3}$ İstanbul Medipol Üniversitesi, Tıp Fakültesi, Çocuk Nefrolojisi, İstanbul, Türkiye
}

ORCID ID: N.B.C. 0000-0002-0141-7065; H.K.D. 0000-0002-0560-1580; Ö.Y. 0000-0002-3582-5075

Attf/Citation: Can NB, Dursun HK, Yavascan O. Karaciğer ve böbrek nakli olan çocuk hastada plesiomonas shigelloides gastroenteriti. Çocuk Dergisi - Journal of Child 2020;20(2):80-82. https://doi.org/10.26650/jchild.2020.2.788902

öz

Plesiomonas hastalığında altta yatan risk faktörünü tanımlayan bilgiler çoklu vaka raporlarından elde edilmiştir. İmmün sistemi baskılanmış hastalar ve yabancı ülkelere seyahat öyküsü Plesiomonas gastroenteritiyle ilişkili önemli risk faktörleridir. Plesiomonas shigelloides, farklı derecelerde ishal kliniğine yol açabilen ülkemizde nadir görülen bir gastroenterit etkenidir. Sulu ishal, Plesiomonas gastroenteritinin en yaygın klinik sunumudur, tüm hastaların \%50 ila \%88'i bu tip diyare ile başvurmaktadır. Bu yazıda 2012 yılında karaciğer nakli, 2015 yılında böbrek nakli olmuş 11 yaşında kız hastada Plesiomonas shigelloides'e bağlı ortaya çıkan ağır kolera benzeri ishal sırasında yaşanan aşırı sıvı kaybı, akut böbrek hasarı, metabolik asidoz, elektrolit dengesizlikleri, immunsüpresif doz ayarlamaları gibi önemli sorunlar ve çözümleri paylaşılmak istenmiştir.

Anahtar Kelimeler: Plesiomonas shigelloides, Akut gastroenterit, Böbrek nakli, Karaciğer nakli
ABSTRACT

Much of our limited knowledge in this area comes from multiple case reports describing a common underlying risk factor that appeared associated with Plesiomonas illness. Immunocompromised patients and foreign travel is a major major risk factors associated with plesiomonas gastroenteritis. Plesiomonas shigelloides is a rare etiologic agent of gastroenteritis in our country that can lead to different severity of diarrhea. Watery diarrhea is the most common clinical presentation of Plesiomonas gastroenteritis, with between $50 \%$ and $88 \%$ of all patients presenting with this type of diarrhea. In this report, we want to present the difficulties such as acute kidney injury, metabolic acidosis, electrolyte imbalances, immunosupressive dose adjustments of severe cholera-like diarrhea due to Plesiomonas shigelloides in an 11-year-old girl who had liver transplantation in 2012, renal transplantation in 2015.

Keywords: Plesiomonas shigelloides, Acute gastroenteritis, Kidney transplantation, Liver transplantation

\section{GiRiş}

Plesiomonas shigelloides, Enterobacteriaceae ailesinde yer alan Gram-negatif bir basildir. Ülkemizde nadir görülen bir akut gastroenterit etkeniyken Güneydoğu Asya, Afrika ve Latin Amerika'da prevalansı oldukça fazladır. Çiğ, az pişmiş deniz ürünü veya kontamine su tüketmek, bakterinin yaygın olarak görüldügü tropik veya subtropik bölgelere seyahat etmek bulaş riskini arttiran faktörler olabilir $(1,2)$.

Sulu ishal, kolera benzeri ishal veya dizanteri şeklinde farklı klinik tablolar oluşturabilir. İmmünsüpresif hastalarda patojene maruziyet sonrası gastroenterit gelişme ihtimali oldukça yüksektir ve hastalık daha ağır seyredebilir $(1,3)$. Ağır kolera benzeri ishal ile hastanemize başvuran böbrek ve karaciğer nakli olmuş 11 yaşında kız hastanın klinik seyrindeki problemler: yüksek miktarda sıvı kaybı, akut böbrek hasarı, metabolik asidoz, elektrolit dengesizlikleri, immunsü presif doz ayarlamalarıydı. Bu önemli sorunlar ile sorunların çözümleri ve tedavi sürecinin paylaşılması amaçlandı. Ayrıca, özellikle ülkemizde gelişmekte olan sağlık turizmi açısından, Plesiomonas shigelloides gibi firsatçı parazit enfeksiyonlarına dikkat çekilmek istendi.

Sorumlu Yazar/Corresponding Author: Nadire Beyza Can E-mail: nadirebeyzacan@gmail.com

Başvuru/Submitted: 08.04.2019 • Revizyon Talebi/Revision Requested: 05.07.2019 • Son Revizyon/Last Revision Received: 22.07 .2019 • Kabul/Accepted: 25.07.2019 


\section{OLGU}

11 yaşında kız hasta aynı gün başlayan ishal, bul ant, kusma ve ateş şikayetiyle hastanemize başvurdu. Bol sulu, kan ve mukus içermeyen, günde on beş yirmi kereyi bulan ishali olduğu ifade edildi. Caroli hastalığı nedeniyle yedi yıl önce karaciğer, dört yı önce böbrek nakli olan hastanın rutin kontrolleri için Gürcistan'dan Türkiye'ye gelirken yolculuk esnasında şikayetlerinin başladığı, 6 aydır devam eden baş ağrıları nedeniyle psödotümör serebri tanısı aldığı ve halihazırda baş ağrılarının mevcut olduğu öğrenildi. Fizik bakıda genel durumu orta-iyi, 40 $\mathrm{kg}(62 \mathrm{p}) 139 \mathrm{~cm}(14 \mathrm{p}), 1.24 \mathrm{~m}^{2}$, yaşamsal bulguları ateş: $37,5^{\circ} \mathrm{C}$, kalp tepe atımı: 114/dk, kan basıncı: 122/91 mm Hg (<95p/< $95 p)$, solunum sayısı: $20 / d k$, satürasyon: $\% 99$, barsak sesleri a rtmış tı, karında ele gelen kitle saptanmadı, sağ üst kadranda karaciğer nakli, sağ alt kadranda böbrek nakli operasyonlarına ait insizyon skarları izlendi. Dudaklar ve mukozalar kuru, diğer sistem bakıları normal saptandı. Laboratuvar incelemesinde lökosit: $8,38 \times 10^{3} / \mu \mathrm{L}$, eritrosit: $3,83 \times 10^{6} / \mu \mathrm{L}$, hemoglobin: 9,5 $\mathrm{g} / \mathrm{dL}$, hematokrit: $\% 28,2$, trombosit: $331 \times 10^{3} / \mu \mathrm{L}$, sodyum: 133 $\mathrm{mmol} / \mathrm{L}$, potasyum: $3,76 \mathrm{mmol} / \mathrm{L}$, fosfor: $3,74 \mathrm{mg} / \mathrm{dL}$, kalsiyum: 9,59 mg/dL, magnezyum: 1,83 mg/dL, klor: $110,3 \mathrm{mmol} / \mathrm{L}$, üre: 55,5 mg/dL, kreatinin: 1,32 mg/dL, albümin: 4,35 g/dL, alanin aminotransferaz: $31,4 \mathrm{U} / \mathrm{L}$, aspartat aminotransferaz: 32,3 U/L, gamaglutamil transferaz: $30 \mathrm{U} / \mathrm{L}$, alkalen fosfataz: 155 $\mathrm{U} / \mathrm{L}, \mathrm{C}$-reaktif protein: 7,76 $\mathrm{mg} / \mathrm{L}$ ve kan gazı incelemesinde $\mathrm{pH}: 7,30, \mathrm{HCO}_{3}: 16 \mathrm{mmol} / \mathrm{L}$ olarak bulundu. Dışkı makroskobisi yeşil, sulu, mukuslu, mikroskobisinde 2-3 lökosit görüldü, eritrosit görülmedi. Dışkı kültüründe üreme saptanmadı. İshal sıklığı ve miktarı nedeniyle kısa zamanda aşırı sıvı kaybeden hastaya ilk olarak intravenöz sıvı yükleme $(20 \mathrm{cc} / \mathrm{kg} \% 0,9 \mathrm{NaCl})$ sonrasında, orta dehitratasyon (bilinen vücut ağırlığı: 44 kg Mevcut ağırlığı: 40 kg, dehitratasyon derecesi: \%10) kliniğine uygun olarak idame (1860 cc) ve açık kapatma (4000 cc) sıvı tedavisi 24 saatte verilecek şekilde \%5 Dekstroz + \%0,9 $\mathrm{NaCl}$ ile ayarlandı. Kayıpları yakın takibe alındı. Metronidazol $(20 \mathrm{mg} /$ $\mathrm{kg}$ /gün oral) tedavisi başlandı, elektrolit dengesinin korunabilmesi için sıvı içerisine $\mathrm{KCl}(20 \mathrm{mEq} / \mathrm{L})$ eklendi. Böbrek nakilli hastanın potasyum replasmanı sırasında elektrolit düzeyleri yakın takip edildi. Metabolik asidoz için sodyum bikarbonat, $\mathrm{HCO}_{3}$ hedefi 18 kabul edilerek açık hesaplanıp tedaviye eklendi. Hastanın immünsüpresyon için kullandığı mikofenolat ve steroid tedavisine aynen devam edildi. Takrolimus kan düzeyleri, ağır gastroenterit tablosu ve tedaviye eklenen ilaçlarla olan etkileşimleri nedeniyle sürekli değişim gösterebileceği için yakından takip edildi ve ilaç kan düzeyi 3-8 ng/mL olacak şekilde doz ayarlaması yapıldı. Psödotümör serebri nedeniyle daha önce çekilen manyetik rezonans görüntül emesi tekrar incelendi ve normal olarak değerlendirildi. Hastaya lomber ponksiyon ya-

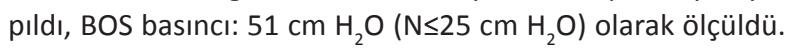
BOS analizinde glukoz: 71,6 mg/dL, total protein: $23 \mathrm{mg} / \mathrm{dL}$, klor: $122,1 \mathrm{mmol} / \mathrm{L}$ olarak bulundu. Hastanın ishal miktarı ve sayısında azalma olmaması üzerine, sıvı replasman tedavisinin yanına anti-ishal tedavi (rasekadotril $3 \times 1,5 \mathrm{mg} / \mathrm{kg}$ oral) eklendi. Dışkı gerçek z amanlı polimeraz z incir reaksiyonu tetkiklerinde Plesiomonas shigelloides pozitif olması sebebiyle $3 \times 500$ mg siprofloksasin tedaviye eklendi. Tekrarlanan kan gazı sonuçlarına göre anti-asidoz tedavi dozları ayarlandı. Hasta yeterli oral alım sağlayamadığından vücut ağırlığı sıvı tedavisiyle korundu, ishal sayısında gerileme olmadığı için anti-ishal tedavinin dozu $4 \times 1,5$ $\mathrm{mg} / \mathrm{kg}$ 'a çıkarıldı. Ağızdan aldığı ilaçlar bulant kusmaya sebep olduğundan sodyum bikarbonat, metronidazol ve siprofloksasin tedavileri için değişiklik yapılarak intravenöz yol tercih edildi. Tedavinin yedinci gününde ishal sayısı 6'ya düşen, kan gazı ve serum potasyum değerleri düzelen olgunun intravenöz sıvı desteği ve potasyum replasmanı kesildi. İzlemi boyunca kan basıncı 120/80 mm Hg düzeylerinde seyretti. Ağrı kesiciye yanıt vermeyen şiddetli baş ağrılarının devam etmesi sebebiyle nöroloji ve göz hastalıklarına danışıldı. Halihazırda kullanmakta olduğu asetazolamid dozu $3 \times 15$ mg/kg'a çıkarıldı. Göz muayenesinde görme alanı defekti ve papilödem tespit edildi. Nörolojinin önerisiyle tekrarlanan lomber ponksiyonda BOS basıncı: 25 $\mathrm{cm} \mathrm{H_{2 }} \mathrm{O}\left(\mathrm{N} \leq 25 \mathrm{~cm} \mathrm{H}_{2} \mathrm{O}\right)$ olarak ölçüldü. Fırsatçı parazit enfeksiyonu olarak tanımlanan akut gastroenterit tablosu tamamen gerilediği için siprofloksasin ve metronidazol tedavisi yatışının 10. gününde sonlandırıldı. Psödotümör serebri tablosu lomber ponksiyon ve asetazolamid tedavisiyle rahatlayan hasta yatŞının 11.gününde taburcu edildi. 9 Dokuz gün sonra kontrole gelen hastanın böbrek fonksiyon testlerinde ılımlı yükseklikler saptansa da bu değerler bazal kreatinin değerleri ile uyumlu bulundu (Grafik 1,2).

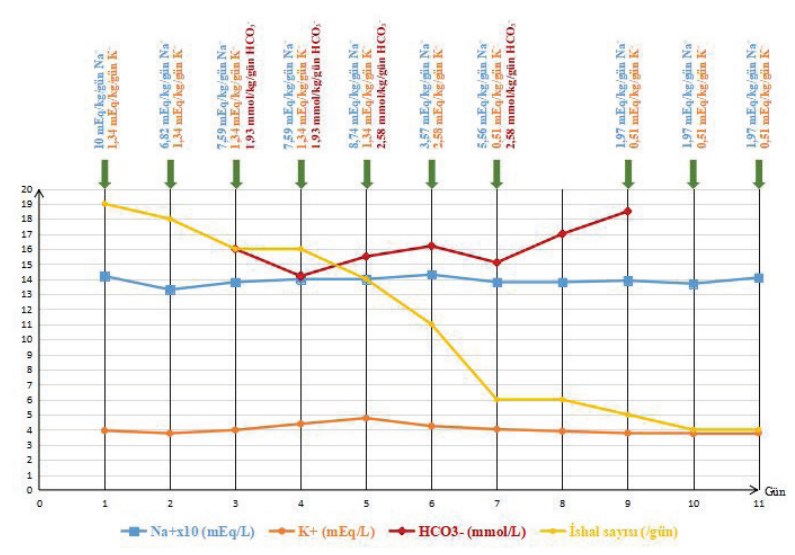

Grafik 1: Hastanın ishal sayısı ile birlikte sıvı elektrolit ve baz durumu ve sıvı elektrolit desteği.

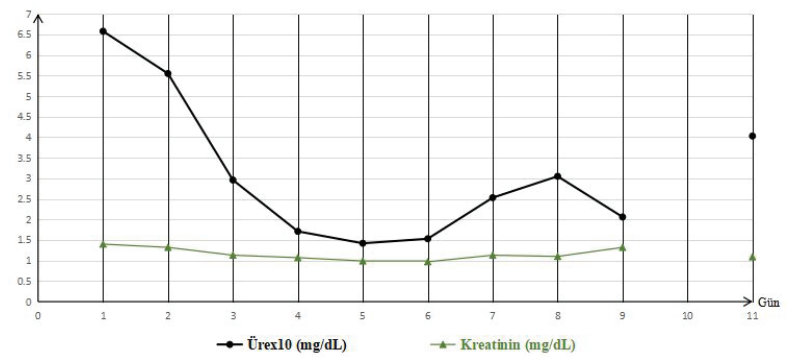

Grafik 2: Hastanın böbrek fonksiyonları.

\section{TARTIŞMA}

Bu olgu, böbrek ve karaciğer nakli olmuş immünsüpresif bir hastada kolera benzeri ishal tablosunun yarattğı sıvı kaybı, SıVı elektrolit dengesizliğinin tedavi edilmesinde yaşanan güçlükler 
nedeniyle sunulmak istendi. Klinik izlem sırasında tedaviye rağmen ishal sayısında azalma olmaması, sıvı elektrolit ve immünsüpresyon düzeylerinin sürekli değişkenlik göstermesi, ishal etkeninin ülkemizde nadir görülen bir gastroenterit etkeni olan Plesiomonas shigelloides olduğunun belirlenmesi ve çocuklarda gastroenterit tedavisinde neredeyse hiç tercih edilmeyen siprofloksasin tedavisinin kullanılması nedeniyle ilginç bulundu.

Plesiomonas shigelloides, immünsüpresif kişilerde daha ağır seyirli ve kolera benzeri gastroenterit kliniğine sebep olabilir (14). Özellikle HIV pozitif olanlar, Plesiomonas ishali geliştirmeye sağlıklı bireylerden daha yatkın olabilirler (5). Bazı çalışmalar ise 19 ila 31 aylık bebekleri (\%33) (6) ve 2 yaşın altındaki çocukları (7). Plesiomonas gastroenteriti açısından yüksek riskli olarak tanımlamışlardır. Güneydoğu Asya ve Afrika coğrafyasında yaz aylarında daha sık görüldüğü bildirilmektedir $(1,3)$. Plesiomonas shigelloides, nadir de olsa menenjit, sepsis, osteomyelit gibi ekstraintestinal enfeksiyonlara da neden olabilir (2). Hepatobilier sistem hastalıklarında, hemokromatoziste, orak hücreli anemide, sirozda, immünsüpresyon durumlarında ekstraintestinal tutulumda artı̧lar görülebilmektedir $(1,3)$.

Bulantı ve kusmanın eşlik ettiği ağır kolera benzeri ishal sonucu oluşan dehidratasyon tablosu, prerenal nedenli böbrek disfonksiyonuna neden olabilir. Ortaya çıkabilecek hipovolemiye bağı böbrek fonksiyon bozukluklarını önlemek için bazen hastaya yoğun Sıvı tedavisinin uygulanması gerekebilir. Böbrek fonksiyonlarını izlemek için kreatinin düzeylerinin takibi önemlidir. Ağır ishal nedeniyle potasyum başta olmak üzere serum elektrolit düzeylerinde dengesizlik ortaya çıkabilir, bu sebeple serum elektrolitlerinin düzenli olarak takip edilmesi önemlidir. Yoğun ishal ile birlikte asit-baz dengesi bozulabilir. Tüm bu riskler sınırda fonksiyonları olan, tübüler anlamda kriz yönetme becerisi yeterli olmayan böbrek nakli olmuş hastalarda çok daha fazla soruna yol açabilir. Bu tür hastalarda sıvı elektrolit kaybının, asit- baz dengesinin ve greft fonksiyonlarının yakın takibi oldukça önemlidir.

Sonuç olarak, aşırı sıvı kaybına yol açan gastroenteritler böbrek nakli hastasında ciddi sıvı- elektrolit ve kan gazı sorunlarına yol açabilir. Bu nedenle yakın takibi oldukça önemlidir. Ayrıca, firsatçı parazit enfeksiyonları özellikle sağlık turizmi hastalarında akılda tutulması gereken önemli sağlık problemlerine yol açabilmektedir.
Hakem Değerlendirmesi: Dış bağımsız.

Yazar Katkıları: Çalışma Konsepti/Tasarım- N.B.C., Ö.Y., H.K.D.; Veri Toplama- N.B.C., H.K.D.; Veri Analizi/Yorumlama- N.B.C., Ö.Y.; Yazı Taslağı- N.B.C., H.K.D.; İçeriğin Eleştirel İncelemesi- Ö.Y.; Son Onay ve Sorumluluk- N.B.C., Ö.Y., H.K.D.; Süpervizyon- Ö.Y.

Çıkar Çatışması: Yazarlar çıkar çatışması beyan etmemişlerdir.

Finansal Destek: Yazarlar finansal destek beyan etmemişlerdir.

Peer Review: Externally peer-reviewed.

Author Contributions: Conception/Design of Study- N.B.C., Ö.Y., H.K.D Data Acquisition- N.B.C., H.K.D.; Data Analysis/Interpretation- N.B.C., Ö.Y.; Drafting Manuscript- N.B.C., H.K.D.; Critical Revision of ManuscriptÖ.Y.; Final Approval and Accountability- N.B.C., Ö.Y., H.K.D.; SupervisionÖ.Y.

Conflict of Interest: Authors declared no conflict of interest.

Financial Disclosure: Authors declared no financial support.

\section{KAYNAKLAR/REFERENCES}

1. J. Michael Janda, Sharon LA, Christopher J. Mclverc. Plesiomonas shigelloides Revisited. Clin Microbiol Rev 2016;29:349-74.

2. Audrey N. Schuetz. Emerging agents of gastroenteritis: Aeromonas, Plesiomonas, and the diarrheagenic pathotypes of Escherichia coli. Seminars in Diagnostic Pathology 2019;36:187-92.

3. Brenden RA, Miller MA, Janda JM. Clinical disease spectrum and pathogenic factors associated with Plesiomonas shigelloides infections in humans. Rev Infect Dis 1988;10:303-16.

4. Janda JM, Abbott SL, Mclver CJ. Plesiomonas shigelloides Revisited. Clin Microbiol Rev 2016;29:349-74.

5. Stock I. Plesiomonas shigelloides: an emerging pathogen with unusual properties. Rev Med Microbiol 2004;15:129-39.

6. Nwokocha ARC, Onyemelukwe NF. Plesiomonas shigelloides diarrhea in Enugu area of the southeastern Nigeria: incidence, clinical and epidemiological features. J Dent Med Sci 2014;13:68-73.

7. Tseng HK, Liu CP, Li WC, Su SC, Lee CM. Characteristics of Plesiomonas shigelloides infection in Taiwan. J Microbiol Immunol Infect. 2002;35:47-52. 